\title{
Association of Diabetes Mellitus with a Combination of Vitamin D Deficiency and Arsenic Exposure in the Korean General Population: Analysis of 2008-2009 Korean National Health and Nutrition Examination Survey Data
}

\author{
Byung-Kook Lee ${ }^{1}$ and Yangho Kim² ${ }^{2 *}$
}

\begin{abstract}
Objectives: We present data from the Korean National Health and Nutritional Examination Survey (KNHANES) 2008-2009 on the combination of vitamin D deficiency and arsenic exposure on diabetes mellitus (DM) in a representative sample of the adult Korean population.

Methods: This study was based on data obtained from the KNHANES 2008-2009, which was conducted for 3 years (2007-2009) using a rolling sampling design that involved a complex, stratified, multistage, probability-cluster survey of a representative sample of the non-institutionalized civilian population in South Korea.

Results: Data analysis revealed that subjects who showed both vitamin D levels in the $1^{\text {st }}$ quartile $(\mathrm{Q})$ and urinary arsenic levels in the $4^{\text {th }} \mathrm{Q}$, had a $302 \%$ increased risk of having DM, as compared with those whose vitamin D and urinary arsenic levels were in the $4^{\text {th }} \mathrm{Q}$ and $1^{\text {st }} \mathrm{Q}$, respectively.

Conclusion: The present study reconfirmed an association of DM with low vitamin D levels and arsenic exposure, and further showed a combination of vitamin D deficiency and arsenic exposure on DM in the general Korean population. To the best of our knowledge, this is the first report describing a combination of vitamin D deficiency and arsenic exposure on DM. The present findings have important public health implications.
\end{abstract}

Keywords: Arsenic, Diabetes, Vitamin D, 25-hydroxyvitamin D

\section{Introduction}

Socioeconomic development and changes in nutrition in the Republic of Korea between the late 1980s and 2005 were accompanied by an increase in the prevalence of type 2 diabetes, from $3 \%$ to $7.3 \%$, and increased concern about diabetes mellitus (DM) [1]. Increasing rates of DM worldwide suggest that the condition is related to environmental factors [2].

In epidemiological studies from Taiwan, Bangladesh, and Mexico, high chronic exposure to inorganic arsenic

\footnotetext{
* Correspondence: yanghokm@nuri.net

${ }^{2}$ Department of Occupational and Environmental Medicine, Ulsan University Hospital, University of Ulsan College of Medicine, Ulsan, South Korea

Full list of author information is available at the end of the article
}

in drinking water $(100 \mu \mathrm{g} / \mathrm{L})$ has been shown to be associated with DM [3-9]. High chronic exposure to inorganic arsenic in occupational settings was also related to higher levels of glycated hemoglobin, a marker of blood glucose levels [10]. The effect of lower levels of exposure to inorganic arsenic on DM risk has also been reported $[2,4,11,12]$. In addition, our recent study showed an association between urinary arsenic and DM in the general Korean population [13].

Vitamin D plays an important role in bone and mineral metabolism, and its deficiency is closely associated with the occurrence of metabolic bone disease, such as rickets in children and osteomalacia in adults. Recently, vitamin $\mathrm{D}$ has been drawing the interest of medical researchers due to its potential role in DM [14,15]. Several

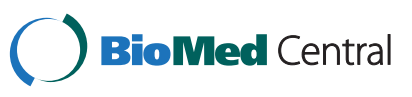


studies have suggested a link between low vitamin D status as measured by 25 -hydroxyvitamin D [25(OH)D] and the occurrence of DM [16-20].

Both arsenic exposure and vitamin D deficiency are commonly encountered public health issues [11,21-25]. However, the combined effect of vitamin D deficiency and arsenic exposure on DM has never been reported. We hypothesized an association of DM with a combination of vitamin D deficiency and arsenic exposure in the general Korean population. To test this hypothesis, we conducted a cross-sectional analysis on the association of vitamin D and arsenic levels with DM status using the Korean National Health and Nutritional Examination Survey (KNHANES) 2008-2009 data set. Our study objective was to evaluate whether there is an association of DM with the combination of vitamin D deficiency and arsenic exposure in a representative sample of the adult Korean population.

\section{Materials and Methods Design and data collection}

This study was based on data obtained from the KNHANES 2008-2009, which represents the second and third years of the KNHANES IV 2007-2009 survey. This survey was conducted for 3 years (2007-2009) using a rolling sampling design that involved a complex, stratified, multistage, probability-cluster survey of a representative sample of the non-institutionalized civilian population in South Korea. Detailed information on the design was provided previously [26]. Briefly, the survey consisted of three components: a health interview survey, a health examination survey, and a nutrition survey. For the present analysis, we used data from a total of 3393 adults (age $\geq 20$ years) who participated in the health examination survey, had documented urinary arsenic measurements, and completed the nutrition survey. All participants provided written consent to participate in the study.

The Institutional Review Board requirement was waived because the KNHANES was conducted by the Korean government in accordance with the internationally agreedupon ethical principles for the conduct of medical research.

Information on age, education, smoking history, alcohol intake, and regular exercise or walking was collected during the health interview. Height and weight measurements were performed with the participants wearing light clothing and no shoes. The body mass index (BMI) was calculated as weight in kilograms divided by the square of the height in meters. The BMI was categorized into three groups: lean $(B M I<18.5)$, normal $(18.5 \leq \mathrm{BMI}<25)$, and obese $(\mathrm{BMI} \geq 25)$. Age as reported at the time of the health interview was categorized into six groups. Residence area was categorized into urban areas (administrative divisions of a city) and rural areas (not classified as administrative divisions of a city).

Education level was categorized into three groups: below high school, high school, and some college or higher. Smoking status was divided into three categories: current smoker, past smoker, and never-smoker. Smoking status was defined based on self-reported cigarette use: Never-smokers had smoked fewer than 100 cigarettes in their lifetime and participants who had smoked 100 or more cigarettes were classified as past or current smokers based on current use. Alcohol consumption was assessed by questioning the participants about their drinking behavior during the month prior to the interview. The participants were asked about their average frequency (days per month) of alcoholic beverage consumption and amount (in $\mathrm{mL}$ ) of alcoholic beverages ingested on a single occasion. The responses were converted into the amount of pure alcohol (in g) consumed per day. The alcohol consumption status was categorized into four groups according to average daily alcohol consumption: non-drinker, light drinker (1-15 g), moderate drinker (16-30 g), and heavy drinker (> $30 \mathrm{~g})$.

Information regarding the frequency of seafood consumption, including fish, shellfish, and seaweed, was obtained from the KNHANES 2008 nutrition survey, which was performed separately on different dates after the health examination. The nutrition survey listed 11 types of seafood that are consumed most frequently in Korea: mackerel, tuna, yellow fish, pollock, anchovies, seafood paste, squid, clams, pickled seafood, brown seaweed, and laver. The overall consumption frequency was categorized into three groups based on the consumption of at least one type of seafood on the nutrition survey checklist: less than once a week, once a week, and more than once a week.

Regular walking was defined as walking for 30 or more minutes at a time at least five times per week, regardless of indoors or outdoors. Regular exercise was defined as moderate exercise (swimming slowly, playing doubles tennis, volleyball, occupational or recreational activities of carrying light objects) on a regular basis for 30 or more minutes at a time at least five times per week or vigorous exercise (running, climbing, cycling fast, swimming fast, football, basketball, jump rope, squash, playing singles tennis, and occupational or recreational activities of carrying heavy objects) for 20 or more minutes at a time at least three times per week. The seasons were classified into four categories as follows: spring (March to May), summer (June to August), fall (September to November), and winter (December to February). DM was defined as a fasting glucose level $\geq 126 \mathrm{mg} / \mathrm{dl}$, current use of antidiabetic medications, or self-reported physician diagnosis of DM. 
Measurement of serum 25-hydroxyvitamin D [25(OH)D)] For the measurement of serum $25(\mathrm{OH}) \mathrm{D}$, blood samples of individual participants were collected during the health examination survey. The blood samples were centrifuged, aliquoted, and frozen to $-70^{\circ} \mathrm{C}$ on site. The frozen serum samples were transported on dry ice to the designated central laboratory of Neodin Medical Institute, a laboratory certified by the Korean Ministry of Health and Welfare in Seoul, Korea.

Blood samples were analyzed within 24 hours after transportation. Serum $25(\mathrm{OH}) \mathrm{D}$ levels were measured using a gamma counter (1470 Wizard, Perkin-Elmer, Finland) with a radioimmunoassay (RIA) kit (DiaSorin, Stillwater, MN). Fasting blood samples were taken in the morning after at least an 8-h fast. Plasma glucose levels were measured using an autoanalyzer (Hitachi 7600 autoanalyzer; Hitachi, Tokyo, Japan).

\section{Measurement of urinary arsenic ( $\mu \mathrm{g} / \mathrm{g}$ creatinine)}

Spot urine samples for total arsenic in urine were collected at the time of health checkups. Total arsenic was measured in 0.1-mL samples of urine by graphite furnace atomic absorption spectrometry with Zeeman background correction (Perkin Elmer AAS 600; Perkin Elmer, Singapore) [27]. All analyses of total urinary arsenic were creatinineadjusted and performed by Neodin Medical Institute. For internal quality assurance and control, commercial reference materials were obtained from Bio-Rad (Lyphochek ${ }^{\circledR}$ Whole Blood Metals Control; Bio-Rad, Hercules, CA). The coefficients of variation were within $0.57 \%-3.20 \%$ for three reference samples of total arsenic (reference values: 66.0, 160.0, and $278.0 \mu \mathrm{g} / \mathrm{L}$ ). As part of external quality assurance and control, the institute passed the German External Quality Assessment Scheme operated by FriedrichAlexander University and also passed the Quality Assurance Program operated by the Korea Occupational Safety and Health Agency. The institute also held a certified license from the Ministry of Labor as one of the designated laboratories for special chemicals, including heavy metals and certain organic chemicals. The method detection limit for total arsenic in urine in the present study was $2.584 \mu \mathrm{g} / \mathrm{L}$. None of the urine samples had arsenic levels below the limit of detection.

\section{Statistical analysis}

Statistical analyses were performed using SAS (Version 9.22, SAS Institute, Cary, NC, USA) and SUDAAN (Release 10.0, Research Triangle Institute, Research Triangle Park, NC, USA), a software package that incorporates sample weights and adjusts analyses for the complex sample design of the survey. Survey sample weights were used in all analyses to produce estimates that were representative of the non-institutionalized civilian Korean population.
The adjusted means [95\% confidence interval (CI)] of serum $25(\mathrm{OH}) \mathrm{D}$ and urinary arsenic were calculated by sex, age group, residence location, season, educational level, smoking status, drinking status, BMI, regular exercise, regular walking, seafood consumption, and DM after adjustment for all other variables in the analysis using the Proc Regress function in SUDAAN.

Next, the odds ratio (OR) and 95\% CI values for having DM were calculated for three models using categories containing a combination of quartiles of $25(\mathrm{OH}) \mathrm{D}$ and urinary arsenic concentration (AsU) while controlling for age, BMI, sex, residence location, season, education level, smoking and drinking status, regular exercise and walking, and seafood consumption. The employed models were as follows:

Model 1: quartiles of 25(OH)D

Model 2: quartiles of AsU

Model 3: combination of quartiles of 25(OH)D and

AsU: group 1): 25(OH)D 4th Q and AsU 1st Q; group 2):

25(OH)D 1st Q and AsU 4th Q.

The adjusted prevalence (\%) and 95\% CI were also obtained using the predicted marginal calculation after the same covariate adjustments for logistic regression analysis from Proc RLOGIST of SUDAAN and are presented in Figure 1, which depicts the graphical comparison of four different groups categorized by a combination of quartiles of 25(OH)D and AsU.

\section{Results}

The arithmetic mean values and 95\% CI of serum 25 $(\mathrm{OH}) \mathrm{D}$ and the geometric mean values and $95 \% \mathrm{CI}$ of AsU of the study participants are listed in Table 1 by the

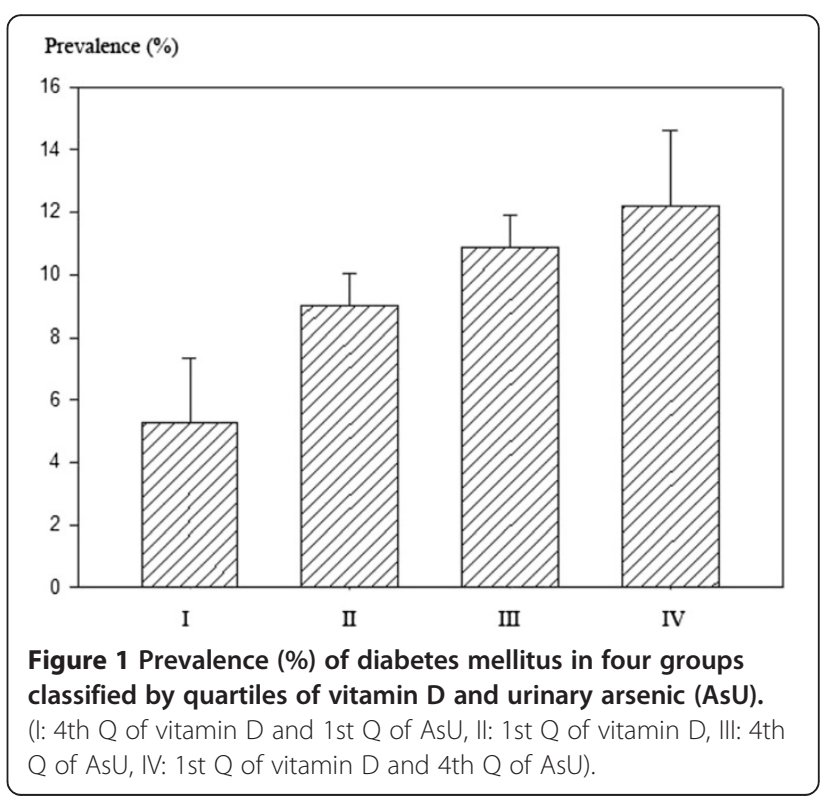


Table 1 Serum 25(OH)D and Urinary arsenic concentration, adjusted for all other variables in the table

\begin{tabular}{|c|c|c|c|c|c|}
\hline \multirow[t]{2}{*}{ Variables } & \multirow[t]{2}{*}{$N$} & \multicolumn{2}{|c|}{ Serum 25(OH)D } & \multicolumn{2}{|c|}{ Urinary arsenic } \\
\hline & & $\mathrm{AM}(95 \% \mathrm{Cl})$ & $\overline{p \text {-value }}$ & GM $(95 \% \mathrm{Cl})$ & $\overline{p \text {-value }}$ \\
\hline \multicolumn{6}{|l|}{ Sex } \\
\hline Men & 1613 & $49.84(48.34-51.34)$ & * & $101.1(96.42-106.1)$ & * \\
\hline Women & 1780 & $42.88(41.62-44.15)$ & 0.000 & $128.7(122.8-134.8)$ & 0.000 \\
\hline
\end{tabular}

Age (years)

$\begin{array}{ll}20-29 & 630 \\ 30-39 & 677 \\ 40-49 & 671 \\ 50-59 & 686 \\ 60+ & 729\end{array}$

$\begin{array}{cc}41.89(40.12-43.66) & * \\ 45.20(43.50-46.90) & 0.001 \\ 45.86(44.37-47.36) & 0.000 \\ 49.30(47.50-51.10) & 0.000 \\ 48.57(46.51-50.63) & 0.000\end{array}$

$69.77(64.74-75.20)$

$100.6(94.77-106.9)$

0.000

$127.1(119.5-135.2) \quad 0.000$

$48.57(46.51-50.63)$

$141.0(132.4-150.1)$

0.000

$155.1(145.2-165.6)$

0.000

Residence location

$\begin{array}{cc}\text { Urban } & 2616 \\ \text { Rural } & 777\end{array}$

$44.81(43.67-45.94)$

$51.30(48.92-53.69)$

$114.4(110.7-118.2)$

$116.9(106.9-127.7)$

0.671

Season

$\begin{array}{cc}\text { Spring } & 905 \\ \text { Summer } & 788 \\ \text { Fall } & 534 \\ \text { Winter } & 1166\end{array}$

44.78 (43.23-46.33)

$47.42(45.57-49.27)$

$108.3(101.5-115.5)$

$46.88(44.99-48.76)$

113.8 (107.5-120.6)

0.222

0.017

116.6 (109.0-124.7)

0.126

45.98 (44.60-47.35)

120.2 (113.9-126.9)

0.027

Education level

Less than high school

45.95 (44.15-47.76)

117.8 (110.9-125.2)

$47.15(45.72-48.58)$

115.1 (109.1-121.4)

0.568

45.48 (43.95-47.01)

112.4 (106.7-118.4)

0.289

Smoking status

Never-smoker
Past smoker

Current smoker

Drinking status

No drink
Mild drink
Moderate drink
Heavy drink

Body Mass Index

$\begin{array}{cc}\text { Lean } & 153 \\ \text { Normal } & 2162 \\ \text { Obese } & 1047\end{array}$

1872

691

825

46.73 (45.45-48.02)

$47.13(45.22-49.03)$

44.06 (42.28-45.83)

44.78 (43.23-46.33)

47.42 (45.57-49.27)

46.88 (44.99-48.76)

45.98 (44.60-47.35)

45.89 (42.93-48.84)

46.12 (44.98-47.26)

46.23 (44.92-47.54)

48.95 (47.07-50.84)

45.62 (44.59-46.65)
0.264

0.706

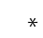

0.727

0.014



0.017

0.055

0.232

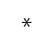

0.876

0.827

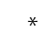

0.000



0.006
120.0 (114.9-125.3)

115.5 (108.1-123.4)

103.7 (97.56-110.3)

0.372

0.000

108.3 (101.5-115.5)

113.8 (107.5-120.6)

0.222

116.6 (109.0-124.7)

0.126

120.2 (113.9-126.9)

0.027

108.7 (96.52-122.4)

114.8 (110.7-119.1)

0.382

116.1 (110.5-122.1)

0.325

111.4 (104.0-119.4)

115.6 (111.8-119.5)

0.351

115.0 (110.6-119.5)

114.8 (110.3-119.5)

0.952 
Table 1 Serum 25(OH)D and Urinary arsenic concentration, adjusted for all other variables in the table (Continued)

\begin{tabular}{|c|c|c|c|c|c|}
\hline \multicolumn{6}{|c|}{ Seafood consumption } \\
\hline $\begin{array}{l}\text { Less than once } \\
\text { a week }\end{array}$ & 310 & $47.76(45.42-50.09)$ & * & $103.5(93.93-114.0)$ & * \\
\hline Once a week & 1031 & $45.47(44.11-46.83)$ & 0.069 & $111.0(105.5-116.9)$ & 0.223 \\
\hline $\begin{array}{c}\text { More than once } \\
\text { a week }\end{array}$ & 2052 & $46.26(45.11-47.41)$ & 0.224 & 118.7 (114.6-122.9) & 0.007 \\
\hline \multicolumn{6}{|l|}{ Diabetes } \\
\hline Yes & 309 & $44.46(42.00-46.91)$ & * & $128.9(117.3-141.8)$ & * \\
\hline No & 3084 & $46.30(45.26-47.35)$ & 0.148 & 113.7 (110.2-117.2) & 0.011 \\
\hline
\end{tabular}

*: reference group; AM, arithmetic mean; GM, geometric mean.

categories of sex, age, residence location, season, education level, smoking and drinking status, BMI, regular exercise and walking, seafood consumption, and DM. The mean values were adjusted for all other variables in the table. Overall, the mean serum 25(OH)D and AsU for women $(n=1780)$ were $42.8 \mathrm{nmol} / \mathrm{L}(95 \% \mathrm{CI}, 41.6-44.2$ $\mathrm{nmol} / \mathrm{L}$ ) and $128.7 \mu \mathrm{g} / \mathrm{g}$ creatinine $(95 \% \mathrm{CI}, 122.8-134.8$ $\mu \mathrm{g} / \mathrm{g}$ creatinine), respectively, and the mean levels for men $(n=1613)$ were $49.8 \mathrm{nmol} / \mathrm{L}(95 \% \mathrm{CI}, 48.3-51.3$ $\mathrm{nmol} / \mathrm{L}$ ) and $101.1 \mu \mathrm{g} / \mathrm{g}$ creatinine $(95 \mathrm{CI}, 96.4-106.1 \mu \mathrm{g} / \mathrm{g}$ creatinine), respectively. The serum $25(\mathrm{OH}) \mathrm{D}$ level was significantly higher in men than in women, but the AsU was significantly lower in men than in women. Both levels were significantly higher with increasing age. The mean $25(\mathrm{OH}) \mathrm{D}$ levels of individuals living in rural areas were significantly higher than those in urban areas, but no difference was observed in the AsU between urban and rural areas. Individuals tested in the spring and winter, the seasons with the lowest amount of sun exposure, had significantly lower serum $25(\mathrm{OH}) \mathrm{D}$ levels than individuals tested in the seasons with the greatest amount of sun (i.e., summer and fall). On the other hand, the mean AsU levels were significantly higher in the winter as compared to the spring. While education level and BMI did not reveal any mean differences in either serum 25(OH)D or urinary arsenic, current smokers had significantly lower mean levels in both as compared with never-smokers. AsU levels were significantly higher in people who drink heavily as compared to those who did not drink. The mean levels of 25 $(\mathrm{OH}) \mathrm{D}$ were higher in people who walked or exercised regularly, and the mean levels of urinary arsenic were higher in people who ate more seafood. No mean difference in $25(\mathrm{OH}) \mathrm{D}$ was observed between diabetic statuses, while a significantly higher mean level of AsU was observed in diabetic subjects.

Subjects whose $25(\mathrm{OH}) \mathrm{D}$ levels were in the 1st Q category had a tendency toward an increased risk of having $\mathrm{DM}$ as compared with those whose $25(\mathrm{OH}) \mathrm{D}$ levels were in 4th $\mathrm{Q}$ although the difference was not statistically significant (model 1)(Table 2). The risk of having DM was 1.65 times higher in the group categorized as having urinary arsenic in the 4th $\mathrm{Q}$, as compared with those who were in the category of AsU in the 1st Q (model 2). The risk of having DM was 3.02 times higher in the group categorized as $25(\mathrm{OH}) \mathrm{D}$ in the 1 st $\mathrm{Q}$ and urinary arsenic in the 4th $\mathrm{Q}$, as compared with those who were in the category of 25 $(\mathrm{OH}) \mathrm{D}$ in the 4th $\mathrm{Q}$ and AsU in the 1st Q (model 3).

The adjusted prevalence (\%) and 95\% CI of DM were also obtained using predicted marginal calculations, and are presented in Figure 1 to depict the graphical comparison of the four different groups categorized with a combination of quartiles of 25(OH)D and AsU levels. Those whose $25(\mathrm{OH}) \mathrm{D}$ levels were in the 4th $\mathrm{Q}$ and AsU were in the 1st Q had a 5.29\% prevalence of DM, whereas those in the worst group with levels in the 1st $\mathrm{Q}$ of $25(\mathrm{OH}) \mathrm{D}$ and 4th $\mathrm{Q}$ of AsU had a $12.19 \%$ prevalence of DM, respectively.

\section{Discussion}

The present study focused on vitamin D deficiency and arsenic exposure, which are environmental risk factors for DM $[4,11-20]$ and are commonly encountered public health issues $[8,11,21-23,25]$.

In the present study, subjects whose 25(OH)D levels were in the 1st Q and whose AsU levels were in the 4th $\mathrm{Q}$ had a 302\% increased risk of having DM as compared with those whose $25(\mathrm{OH}) \mathrm{D}$ and AsU levels were in the 4th $\mathrm{Q}$ and 1st Q, respectively. The overall prevalence of DM in our study population was 9.11\% (309/3393). From predicted marginal calculations, the adjusted prevalence ranged from 5.29 to $12.19 \%$, depending on the levels of 25(OH)D and AsU. The present study reconfirmed an association of DM with low vitamin D levels and arsenic exposure, and further showed an association of DM with the combination of vitamin D deficiency and arsenic exposure in the general Korean population. To the best of our knowledge, this is the first report describing an association of DM with the combination of vitamin D deficiency and arsenic exposure.

Animal and in vitro model systems have indicated that arsenic exposure can potentially increase the risk of DM through inhibition of insulin-dependent glucose uptake 
Table 2 Adjusted OR ( $95 \% \mathrm{CI})$ of Korean adults having diabetes mellitus by category of combination of 25-hydroxyvitamin D quartile and urinary arsenic quartile, adjusted for covariates\#

\begin{tabular}{|c|c|c|c|}
\hline Model & Independent variables & Odds ratio & 95\% Confidence Interval \\
\hline \multicolumn{4}{|c|}{ Model 1} \\
\hline & Age (years) & 1.060 & $1.046 \sim 1.074$ \\
\hline & Body mass index $\left(\mathrm{kg} / \mathrm{m}^{2}\right)$ & 1.162 & $1.108 \sim 1.218$ \\
\hline & Sex & & \\
\hline & Men & Ref & \\
\hline & Women & 1.053 & $0.697 \sim 1.351$ \\
\hline & Quartile of serum 25-hydroxyvitamin D & & \\
\hline & 1. 1st Q ( $\leq 30.02)$ & 1.250 & $0.827 \sim 1.888$ \\
\hline & 2. 2nd Q $(31.02<\mathrm{Q} \leq 44.11)$ & 1.395 & $0.931 \sim 2.091$ \\
\hline & 3. 3rd Q (44.11< Q $\leq 55.99)$ & 1.216 & $0.804 \sim 1.838$ \\
\hline & 4. 4th Q ( > 55.99) & Ref & \\
\hline \multicolumn{4}{|l|}{ Model 2} \\
\hline & Age (years) & 1.057 & $1.042 \sim 1.071$ \\
\hline & Body mass index $\left(\mathrm{kg} / \mathrm{m}^{2}\right)$ & 1.163 & $1.108 \sim 1.220$ \\
\hline & Sex & & \\
\hline & Men & Ref & \\
\hline & Women & 1.015 & $0.679 \sim 1.518$ \\
\hline & Quartile of urinary arsenic & & \\
\hline & 1. 1st Q ( $\leq 69.67)$ & Ref & \\
\hline & 2. 2nd Q (69.67 < Q $\leq 114.86)$ & 1.056 & $0.646 \sim 1.727$ \\
\hline & 3. 3rd Q $(114.86<\mathrm{Q} \leq 159.48)$ & 1.200 & $0.742 \sim 1.940$ \\
\hline & 4. 4th Q ( > 159.48) & 1.654 & $1.038 \sim 1.518$ \\
\hline \multicolumn{4}{|l|}{ Model 3} \\
\hline & Age (years) & 1.074 & $1.026 \sim 1.123$ \\
\hline & Body mass index $\left(\mathrm{kg} / \mathrm{m}^{2}\right)$ & 1.260 & $1.134 \sim 1.400$ \\
\hline & Sex & & \\
\hline & Men & Ref & \\
\hline & Women & 0.776 & $0.239 \sim 2.519$ \\
\hline & Combination of Vitamin D \& AsU & & \\
\hline & 1. Vitamin $\mathrm{D} 4 \mathrm{th} \mathrm{Q}+\mathrm{AsU} 1 \mathrm{stQ}$ & Ref & \\
\hline & 2. Vitamin $\mathrm{D} 1 \mathrm{stQ}+\mathrm{AsU} 4$ thQ & 3.023 & $1.004 \sim 9.105$ \\
\hline
\end{tabular}

\#Covariates: residence location (urban or rural), season, education level, smoking \& drinking status, regular exercise \& walking and seafood consumption; $\mathrm{Q}$, quartile; $\mathrm{AsU}$, urinary arsenic (g/g creatinine).

[28] and insulin signaling [29], impairment of insulin secretion and transcription in pancreatic beta cells [30], and modification of the expression of genes involved in insulin resistance [30]. The mechanisms underlying the potential association between DM and $25(\mathrm{OH}) \mathrm{D}$ are unclear. The $25(\mathrm{OH}) \mathrm{D}$ level may have an impact on many factors, including pancreatic beta cell function, insulin action, and systemic inflammation [31]. Accumulating evidence indicates that vitamin $\mathrm{D}$ may be useful in the prevention and treatment of DM. Vitamin D supplementation in participants with vitamin $\mathrm{D}$ deficiency has been shown to result in improved glucose tolerance [32]. The mechanisms underlying the potential association of DM with the combination of $25(\mathrm{OH}) \mathrm{D}$ and arsenic remain to be clarified.

The present findings have several implications with respect to environmental health. First, the present results indicate the importance of assessing vitamin D levels or arsenic exposure when addressing their association with DM. Second, vitamin D deficiency may be critical for assessing the risk of DM in people living in regions in which arsenic exposure is endemic, or in the vicinity of highly contaminated areas, such as abandoned metal mines without strict environmental controls, or arsenic- 
emitting factories. Considering the high prevalence of vitamin D deficiency [21-23], these findings have important public health implications in the general population.

The present study had several important strengths. First, we used serum 25(OH)D concentration as an indicator of vitamin $\mathrm{D}$ levels, which reflects vitamin $\mathrm{D}$ obtained from diet, supplements, and cutaneous synthesis. Second, relevant DM risk factors and confounders, including seafood consumption, were adjusted for. Third, the study was performed in a representative sample of the general Korean population. Finally, rigorous quality control of the study procedures was ensured in the KNHANES.

The present study had some limitations. First, our associations were obtained from a cross-sectional analysis. We cannot completely exclude the possibility of reverse causality. A third factor might be a common link which produces the association: Low physical activity might be associated with both DM and low vitamin D. Therefore, a causal relationship between serum vitamin $\mathrm{D}$ level and arsenic level and DM cannot be inferred. A prospective study, in which arsenic or vitamin D levels are determined before the development of disease, will be required to establish the causal nature of these associations.

Second, data on sun exposure and dietary vitamin D intake were not available. Instead, we obtained data regarding the participants' exercise and walking habits, which presumably provide an estimate of each subject's sunlight exposure [33]. We also adjusted for assumed seasonal exposure. Third, we did not perform species analysis of arsenic and could not rule out contributions of organic arsenic such as arsenobetaine and arsenosugars mainly derived from seafood to total AsU levels [13,34,35]. Instead, we adjusted for seafood consumption as the main sources of organic arsenic. Fourth, family history is a very important risk factor for DM; however, these data were not available in the 2008-2009 KNHANES.

\section{Conclusion}

In conclusion, we showed an association of DM with the combination of vitamin D deficiency and arsenic exposure in the general Korean population.

\section{Competing interests}

The authors declare that they have no competing interests.

\section{Authors' contributions \\ All authors had access to the data and played a role in writing this manuscript: study concept and design (YK); acquisition, statistical analysis and interpretation of data (B-KL); drafting of the manuscript (YK); critical revision of the manuscript (B-KL); All authors read and approved the final manuscript.}

\footnotetext{
Author details

${ }^{1}$ Institute of Environmental \& Occupational Medicine, Soonchunhyang University 646 Eupnae-ri, Shinchang-myun, Asan-siChoongnam 336-745, South Korea. ${ }^{2}$ Department of Occupational and Environmental Medicine, Ulsan University Hospital, University of Ulsan College of Medicine, Ulsan, South Korea.
}

Received: 8 October 2012 Accepted: 18 February 2013

Published: 21 May 2013

\section{References}

1. Korean Ministry of Health and Welfare: The fourth Korean National Health and Nutrition Examination Survey. Seoul: Korean Ministry of Health and Welfare; 2007

2. Longnecker MP, Daniels JL: Environmental contaminants as etiologic factors for diabetes. Environ Health Perspect 2001, 109(Suppl. 6):871-876.

3. Chen CJ, Wang SL, Chiou JM, Tseng CH, Chiou HY, Hsueh YM, et al: Arsenic and diabetes and hypertension in human populations: a review. Toxicol Appl Pharmacol 2007, 222:298-304.

4. Coronado-González JA, Del Razo LM, Garcia-Vargas G, Sanmiquel-Salazar F, Escobedode la Peña J: Inorganic arsenic exposure and type 2 diabetes mellitus in Mexico. Environ Res 2007, 104:383-389.

5. Lai MS, Hsueh YM, Chen CJ, Shyu MP, Chen SY, Kuo TL, et al: Ingested inorganic arsenic and prevalence of diabetes mellitus. Am J Epidemiol 1994, 139:484-492.

6. Navas-Acien A, Silbergeld EK, Streeter RA, Clark JM, Burke TA, Guallar E: Arsenic exposure and type 2 diabetes: a systematic review of the experimental and epidemiological evidence. Environ Health Perspect 2006, 114:641-648.

7. Rahman M, Tondel M, Ahmad SA, Axelson O: Diabetes mellitus associated with arsenic exposure in Bangladesh. Am J Epidemiol 1998, 148:198-203.

8. Tseng CH, Tai TY, Chong CK, Tseng CP, Lai MS, Lin BJ, Chiou HY, Hsueh YM, Hsu KH, Chen CJ: Long-term arsenic exposure and incidence of noninsulin-dependent diabetes mellitus: a cohort study in arseniasishyperendemic villages in Taiwan. Environ Health Perspect 2000, 108:847-851.

9. Wang SL, Chiou JM, Chen CJ, Tseng CH, Chou WL, Wang CC, Wu TN, Chang LW: Prevalence of noninsulin-dependent diabetes mellitus and related vascular diseases in southwestern arseniasis-endemic and nonendemic areas in Taiwan. Environ Health Perspect 2003, 111:155-159.

10. Jensen GE, Hansen ML: Occupational arsenic exposure and glycosylated haemoglobin. Analyst 1998, 123:7-80.

11. Navas-Acien A, Silbergeld EK, Pastor-Barriuso R, Guallar E: Arsenic exposure and prevalence of type 2 diabetes in US adults. JAMA 2008, 300:814-822

12. Zierold KM, Knobeloch L, Anderson H: Prevalence of chronic diseases in adults exposed to arsenic contaminated drinking water. Am J Public Health 2004, 94:1936-1937.

13. Kim Y, Lee BK: Association between urinary arsenic and diabetes mellitus in the Korean general population according to KNHANES 2008. Sci Total Environ 2011, 409:4054-4062.

14. Mattila C, Knekt P, Mannisto S, Rissanen H, Laaksonen MA, Montonen J, Reunanen A: Serum 25-hydroxyvitamin D concentration and subsequent risk of type 2 diabetes. Diabetes Care 2007, 30:2569-2570.

15. Pittas AG, Lau J, Hu FB, Dawson-Hughes B: The role of vitamin D and calcium in type 2 diabetes. A systematic review and meta-analysis. $J$ Clin Endocrinol Metab 2007, 92:2017-2029.

16. Choi HS, Kim KA, Lim CY, Rhee SY, Hwang YC, Kim KM, Kim KJ, Rhee Y, Lim SK: Low serum vitamin $D$ is associated with high risk of diabetes in Korean adults. J Nutr 2011, 141:1524-1528.

17. Hypponen E, Boucher BJ, Berry DJ, Power C: 25-hydroxyvitamin D, IGF-1, and metabolic syndrome at 45 years of age: a cross sectional study in the 1958 British Birth Cohort. Diabetes 2008, 57:298-305.

18. Lu L, Yu Z, Pan A, Hu FB, Franco OH, Li H, Li X, Yang X, Chen Y, Lin X: Plasma 25-hydroxyvitamin D concentration and metabolic syndrome among middle-aged and elderly Chinese individuals. Diabetes Care 2009 32:1278-1283.

19. Scragg R, Sowers MF, Bell C: Serum 25-hydroxyvitamin D, diabetes and ethnicity in the Third National Health and Nutrition Examination Survey. Diabetes Care 2004, 27:2813-2818.

20. Lee BK, Park S, Kim Y: Age- and gender-specific associations between low serum 25-hydroxyvitamin $\mathrm{D}$ level and type 2 diabetes in the Korean general population: analysis of 2008-2009 Korean National Health and Nutrition Examination Survey data. Asia Pac J Clin Nutr 2012, 21:536-546

21. Choi HS, Oh HJ, Choi H, Choi WH, Kim JG, Kim KM, Kim KJ, Rhee Y, Lim SK: Vitamin $D$ insufficiency in Korea-a greater threat to younger generation: the Korea National Health and Nutrition Examination Survey (KNHANES) 2008. J Clin Endocrinol Metab 2011, 96:643-651. 
22. Ginde AA, Liu MC, Camargo CA Jr: Demographic differences and trends of vitamin D insufficiency in the US population, 1988-2004. Arch Intern Med 2009, 169:626-632.

23. Lips P, Hosking D, Lippuner K, Norquist JM, Wehren L, Maalouf G, Ragi-Eis S, Chandler J: The prevalence of vitamin $D$ inadequacy amongst women with osteoporosis: an international epidemiological investigation. J Intern Med 2006, 260:245-254.

24. Tseng CH, Tseng CP, Chiou HY, Hsueh YM, Chong CK, Chen CJ: 2006. Epidemiologic evidence of diabetogenic effect of arsenic. Toxicol Lett 2006, 133:69-76.

25. Xia Y, Liu J: An overview on chronic arsenism via drinking water in PR China. Toxicology 2004, 198:25-29.

26. Kim Y, Lee BK: Iron deficiency increases blood manganese level in the Korean general population according to KNHANES 2008. Neurotoxicology 2011, 32:247-254

27. Nixon DE, Mussmann GV, Eckdahl SJ, Moyer TP: Total arsenic in urine: palladiumpersulfate vs. nickel as a matrix modifier for graphite furnace atomic absorption spectrophotometry. Clin Chem 1991, 37:1575-1579.

28. Walton FS, Harmon AW, Paul DS, Drobna Z, Patel YM, Styblo M: Inhibition of insulindependent glucose uptake by trivalent arsenicals: possible mechanism of arsenicinduced diabetes. Toxicol Appl Pharmacol 2004, 198:424-433.

29. Paul DS, Harmon AW, Devesa V, Thomas DJ, Styblo M: Molecular mechanisms of the diabetogenic effects of arsenic: inhibition of insulin signaling by arsenite and methylarsonous acid. Environ Health Perspect 2007, 115:734-742.

30. Diaz-Villaserior A, Sanchez-Soto MC, Cebrian ME, Ostrosky-Wegman P, Hiriart M: Sodium arsenite impairs insulin secretion and transcription in pancreatic betacells. Toxicol Appl Pharmacol 2006, 214:30-34.

31. Maestro B, Campion J, Davila N, Calle C: Stimulation by 1,25-dihydroxyvitamin D3 of insulin receptor expression and insulin responsiveness for glucose transport in U-937 human promonocytic cells. Endocr J 2000, 47:383-391.

32. Mathieu C, Gysemans C, Giulietti A, Bouillon R: Vitamin D and diabetes. Diabetologia 2005, 48:1247-1257.

33. Ahonen MH, Tenkanen L, Teppo L, Hakama M, Tuohimaa P: Prostate cancer risk and prediagnostic serum 25-hydroxyvitamin D levels (Finland). Cancer Causes Control 2000, 11:847-852.

34. Cullen WR, Reimer KJ: Arsenic speciation in the environment. Chem Rev 1989, 89:713-764.

35. Francesconi KA, Edmonds JS: Arsenic and marine organisms. Adv Inorg Chem 1997, 44:147-189.

doi:10.1186/2052-4374-25-7

Cite this article as: Lee and Kim: Association of Diabetes Mellitus with a Combination of Vitamin D Deficiency and Arsenic Exposure in the Korean General Population: Analysis of 2008-2009 Korean National Health and Nutrition Examination Survey Data. Annals of Occupational and Environmental Medicine 2013 25:7.

\section{Submit your next manuscript to BioMed Central and take full advantage of:}

- Convenient online submission

- Thorough peer review

- No space constraints or color figure charges

- Immediate publication on acceptance

- Inclusion in PubMed, CAS, Scopus and Google Scholar

- Research which is freely available for redistribution 